\title{
Activated protein C differentially regulates both viability and differentiation of osteoblasts mediated by bisphosphonates
}

\author{
You-Jin Lee ${ }^{1}$, Jae-Kyo Jeong ${ }^{1}$, Jae-Won Seol ${ }^{1}$, Meilang Xue ${ }^{2}$, Chris Jackson ${ }^{2}$ and Sang-Youel Park ${ }^{1}$ \\ Activated protein C (APC) is a cytoprotective anticoagulant that can promote cutaneous healing. We examined the effect of \\ APC on viability and differentiation of the osteoblastic line, MG63, in the presence and absence of bisphosphonates (BPs). \\ Osteoblasts were cultured and treated for 24 or $48 \mathrm{~h}$ with Alendronate (Aln), Zoledronate (Zol) or Pamidronate (Pam) at \\ concentrations ranging from $10^{-4}$ to $10^{-6} \mathrm{M}$. Cell differentiation was measured using type 1 collagen production, Alizarin red \\ staining and alkaline phosphatase activity, whereas cell viability was assessed using MTT and crystal violet assays. All three \\ BPs induced MG63 cell death in a dose- and time-dependent manner. Pam- and Zol-related cell death was prevented by APC \\ treatment; however, cell death induced by Aln was accelerated by APC. APC induced MG63 cell differentiation that was \\ enhanced by Aln, but inhibited by Pam or Zol. Endothelial protein C receptor (EPCR) was expressed by MG63 cells and \\ mediated the protective effect of APC on Zol-induced viability. In summary, we have demonstrated that (1) APC favorably \\ regulates MG63 viability and differentiation toward bone growth, (2) APC differentially regulates the effects of specific BPs \\ and (3) at least part of the effects of APC is mediated through EPCR. These findings highlight the potential importance \\ of the PC pathway in bone physiology and provide strong evidence that APC may influence bone cells and has potential \\ to be a therapeutic drug for bone regeneration, depending on concurrent BP treatment. \\ Experimental \& Molecular Medicine (2013) 45, e9; doi:10.1038/emm.2013.16; published online 15 February 2013
}

Keywords: activated protein C; bisphosphonates; EPCR; MG63; osteoblast

\section{INTRODUCTION}

Bisphosphonates (BPs) are currently the most important class of antiresorptive drugs used for the treatment of metabolic bone diseases and they are frequently being used in oncology to treat bone complications. In osteoporosis, the BPs have made a major contribution to how clinicians manage the disease and are regarded as first-line therapy. However, recently there have been reports of osteonecrosis of the jaw (ONJ) associated with their long-term use in osteoporosis and oncology. ${ }^{1-3}$ The mechanism by which BPs cause ONJ is uncertain. Low bone turnover has been assumed to be a contributing factor to ONJ, because the therapeutic action of these drugs is to reduce turnover. However, it is also possible that $\mathrm{ONJ}$ is contributed to by direct toxicity of BPs to bone or soft tissue cells. ${ }^{4}$

Although the main effect of BPs in vivo is thought to be on osteoclast activity, the effects on cells of the osteoblast lineage have also been described. BPs at very low concentrations can protect against apoptosis induced by etoposide and corticosteroids in osteoblasts. ${ }^{5,6}$ BPs can stimulate mineralized bone nodule formation in vitro ${ }^{7}$ and promote differentiation of mesenchymal stem cells into osteoblasts. ${ }^{8}$ Although these results raise the possibility that BPs have positive effects on osteoblasts as well as antiresorptive properties in osteoclasts, there is accumulating evidence from studies in humans and experimental animals that BPs actually suppress bone formation in $v i v o^{9}$ and impair the anabolic response to parathyroid hormone. ${ }^{10-15}$

Activated protein C (APC) plays a central role in physiological anticoagulation, and has more recently been shown to be a potent anti-inflammatory mediator and have cytoprotective properties. ${ }^{16} \mathrm{APC}$ upregulates the angiogenic promoters, vascular endothelial growth factor, monocyte chemoattractant protein-1 and matrix metalloproteinase-2 (MMP-2) in cultured human skin fibroblasts, keratinocytes and endothelial cells. By stimulating angiogenesis and re-epithelialization, APC promotes cutaneous wound healing in rodents ${ }^{3}$ and humans with chronic wounds. ${ }^{17}$ In this study, we

\footnotetext{
${ }^{1}$ Bio-Safety Research Institute, Chonbuk National University, College of Veterinary Medicine, Jeonju, South Korea and ${ }^{2}$ Institute of Bone and Joint Research, University of Sydney, Kolling Institute, Royal North Shore Hospital, St Leonards, New South Wales, Australia Correspondence: Professor S-Y Park, College of Veterinary Medicine, Chonbuk National University, Jeonju 561-756, South Korea. E-mail: sypark@chonbuk.ac.kr
}

Received 24 August 2012; revised 20 November 2012; accepted 3 December 2012 
examined the effect of APC on viability and differentiation of the osteoblastic line, MG63, in the presence and absence of BPs.

\section{MATERIALS AND METHODS}

\section{Culture and experimental treatment of human osteoblastoma MG63 cells}

Human osteoblastoma MG63 cells were maintained in Dulbecco's modified Eagle's medium containing 10\% fetal calf serum and were

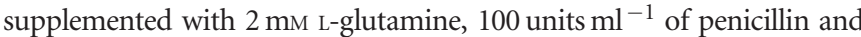
$100 \mu \mathrm{g} \mathrm{ml}^{-1}$ of streptomycin. Before treatment, cells were preincubated for $2 \mathrm{~h}$ in Dulbecco's Modified Eagle's medium with 2\% MMP-free fetal calf serum (basal medium) and then transferred to a fresh basal medium. Cells were treated with recombinant human APC (Eli Lilly, Indianapolis, IN, USA), RCR252 (endothelial protein C receptor (EPCR) blocking antibody, provided by Professor K Fukudome, Department of Immunology, Saga Medical School, Nabeshima, Saga, Japan), alendronate $(\mathrm{Aln})$, pamidronate $(\mathrm{Pam})$, zoledronate $(\mathrm{Zol})$ and lovastatin.

\section{Cell viability}

The cells were plated in 12 or 24 wells and pretreated with $0-10 \mu \mathrm{M}$ APC for $0-2 \mathrm{~h}$. The cells were then incubated with Aln, Pam, Zol and lovastatin for an additional experimental hour. The cell morphology was photographed under light microscope, and cell viability was determined by crystal violet staining. Briefly, the cells were stained for $10 \mathrm{~min}$ at room temperature with staining solution $(0.5 \%$ crystal violet in 30\% ethanol and 3\% formaldehyde), washed four times with water and then dried. The cells were then lysed with $1 \%$ sodium dodecyl sulfate solution and the absorbance was measured at $550 \mathrm{~nm}$. The cell viability was calculated based on the relative dye intensity compared with controls.

\section{MTT assay}

The colorimetric MTT (3-[4,5-Dimethylthiazol-2-yl]-2,5-diphenyl tetrazolium bromide) assay was performed to quantitate the effect of different test agents on cell viability and to standardize loading of gels. Briefly, $2 \times 10^{4}$ cells per well were seeded in a 96-well microplate in a final volume of $200 \mu$ l, incubated overnight, and treated with test agents for $24 \mathrm{~h}$. At $3 \mathrm{~h}$ before the completion of the treatment, $10 \mu \mathrm{l}$ of $5 \mathrm{mg}$ per ml MTT (Sigma Aldrich, St Louis, MO, USA) was added to the cells and cells were further incubated for $3 \mathrm{~h}$. The MTT solution was then removed and replaced by $100 \mu$ dimethylsulfoxide, and the plates were shaken for $3 \mathrm{~min}$. The optical density was determined at a wavelength of $570 \mathrm{~nm}$.

\section{Western blot}

MG63 cells were washed three times with phosphate-buffered saline and lysed with lysis buffer $(0.15 \mathrm{M} \mathrm{NaCl}, 0.01 \mathrm{~mm}$ PMSF, $1 \% \mathrm{NP}-40$, $0.02 \mathrm{M}$ Tris, $6 \mathrm{M}$ urea $/ \mathrm{H}_{2} \mathrm{O}$ ). Cell lysates were centrifuged at $10000 \mathrm{~g}$ for $15 \mathrm{~min}$, and total protein concentration was determined using the bicinchoninic acid (BCA) Protein Assay kit (Pierce Biotechnology, Rockford, IL, USA). Equal amounts of protein were separated by $8-15 \%$ sodium dodecyl sulfate-polyacrylamide gel electrophoresis and subjected to western blotting. The primary antibodies used in this experiment were anti-human collagen type 1 antibody (MP Biomedicals, OH, USA); anti-phosphorylated form of extracellular signalregulated kinase (ERK) and anti-EPCR antibody (1:500 or 1:1000 dilutions, Santa Cruz Biotechnology, Santa Cruz, CA, USA); and anticleaved caspase-3 antibody (R\&D Systems, Minneapolis, MN, USA). Immunoreactivity was detected using the ECL detection system (Amersham, Piscataway, NJ, USA).

\section{Zymography}

MMP-2 activity in culture supernatants was analyzed by gelatin zymography, as previously described. ${ }^{18}$

\section{Immunofluorescent staining}

Cultured MG63 cells on permanox slides were fixed with cold acetone and blocked by $5 \%$ horse serum in phosphate-buffered saline, and incubated with rabbit anti-human active caspase-3 antibody (R\&D Systems), rabbit anti-human EPCR antibody (Santa Cruz Biotechnology) and mouse anti-human collagen type 1 (MP Biomedicals) overnight at $4{ }^{\circ} \mathrm{C}$. After washing with phosphate-buffered saline, cells were incubated with anti-rabbit IgG conjugated with Cy3 (red) and anti-goat IgG conjugated with FITC (green) (Invitrogen, Carlsbad, CA, USA). Cells were washed with phosphate-buffered saline, mounted with ProLongGold anti-fade reagent with or without DAPI (Invitrogen) and observed with a fluorescence microscope (Nikon ECLIPSE 80i; Nikon, Tokyo, Japan).

\section{Assay of alkaline phosphatase activity}

Alkaline phosphatase (ALP) activity in cell homogenates and culture media were assayed using the assay mixtures containing $0.1 \mathrm{M}$ 2-amino-2-methyl-1-propanol, $1 \mathrm{~mm}^{\mathrm{MgCl}_{2}}$ and $8 \mathrm{~mm}$ p-nitrophenyl phosphate disodium (Sigma-Aldrich). After $30 \mathrm{~min}$ of incubation at $37^{\circ} \mathrm{C}$, the absorbance was read at $405 \mathrm{~nm}$. The protein assay was performed with the BCA Protein Assay reagent (Pierce Biotechnology). Each value was normalized to the protein concentration.

\section{Assay of mineralization}

Mineralization of MG63 cells was determined in 6-well or 12-well plates using Alizarin red stainings. The cells were fixed with ice-cold $70 \%$ ethanol and stained with Alizarin red to detect calcification. For quantification, cells stained with Alizarin red $(n \geqslant 6)$ were destained with dimethylsulfoxide, and then the extracted stain was transferred to a 96-well plate, and the absorbance at $550 \mathrm{~nm}$ was measured using a microplate reader. Each value was normalized to the protein concentration.

\section{RESULTS}

\section{APC differentially affects MG63 differentiation depending} on the presence of specific BPs

To determine the effect of APC on MG63 differentiation, in the presence or absence of BPs, we measured collagen production, Alizarin red staining and ALP activity. Type 1 collagen expression was assessed by immunoflourescence and western blotting. APC dose-dependently increased type 1 collagen expression (Figures $1 \mathrm{a}$ and $\mathrm{b}$ ), whereas the three BPs tested (Aln, Pam and Zol) either reduced or had no effect on collagen levels (Figure 1c). In the presence of BPs, APC was still able to induce collagen production (Figure 1c). Alizarin red, used to determine calcific deposition, was measured on a per-cell basis. Staining was not significantly affected by any BP, although Zol tended to increase the level of staining. APC significantly increased Alizarin red staining under basal conditions and in response to Aln, but not when co-administrated with Pam or Zol (Figure 2a). Similar effects were seen with ALP activity, with APC promoting activity when used alone or in the presence of Aln (Figures $2 \mathrm{~b}$ and $\mathrm{c}$ ), whereas the stimulatory effect of APC was not evident in the presence of Pam or Zol (Figure 2b). 


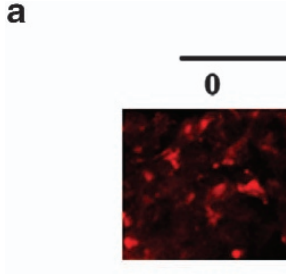

APC (uM)
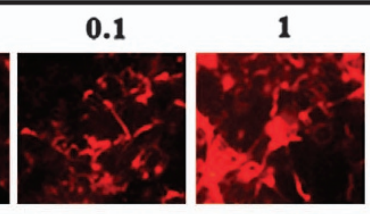

10

b

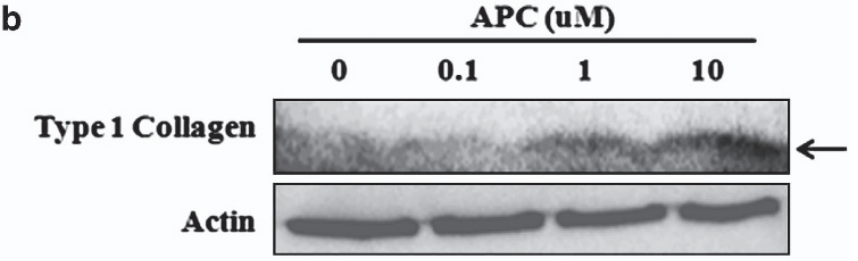

C
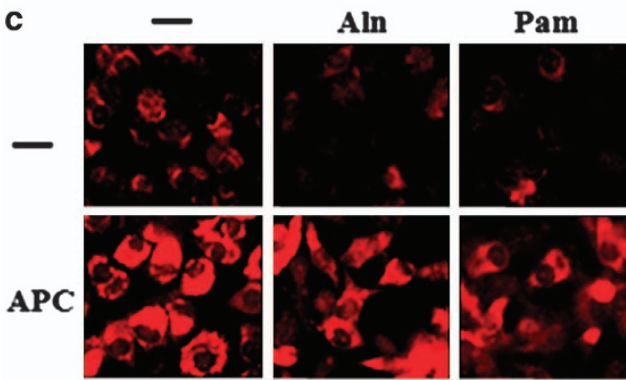

Zol

APC

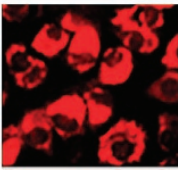

Figure 1 Expression of type 1 collagen by activated protein $C$ (APC) treatment in MG63 cells. MG63 cells were treated with APC $\left(0.1,1\right.$ or $\left.10 \mu \mathrm{g} \mathrm{ml}^{-1}\right)$ for $25 \mathrm{~h}$ and type 1 collagen expression detected by (a) immunofluorescent staining and (b) western blotting. $\beta$-Actin was used to normalize the equal protein loading. (c) Immunofluorescence staining of type 1 collagen in MG63 cells pretreated with APC $\left(10 \mu \mathrm{g} \mathrm{ml}^{-1}\right)$ for $1 \mathrm{~h}$ and then cotreated with bisphosphonates (alendronate (Aln) $50 \mu \mathrm{m}$, pamidronate (Pam) $50 \mu \mathrm{m}$ and zoledronate (Zol) $50 \mu \mathrm{m}$ ) for $24 \mathrm{~h}$.

APC exerts opposing effects on MG63 viability depending on the presence of specific BPs

Cultured MG63 cells were treated for $\sim 48 \mathrm{~h}$ with Zol $(0-200 \mu \mathrm{M})$, Pam $(0-100 \mu \mathrm{M})$, lovastatin $(0-20 \mu \mathrm{M})$ or Aln $(0-100 \mu \mathrm{M})$ and cell viability was measured using MTT and crystal violet assays. Lovastatin, used as a control, dosedependently reduced cell viability at concentrations of 0-20 $\mu \mathrm{M}$ (Figure 3a) and the addition of APC had no effect on lovastatin-reduced cell viability. All three BPs reduced cell viability in a dose-dependent manner (Figures $3 \mathrm{~b}$ and c). Cell death induced by Zol (100 and $200 \mu \mathrm{M})$ and Pam (50 and $100 \mu \mathrm{M})$ was prevented by treatment with $10 \mu \mathrm{g} \mathrm{ml}^{-1}$ APC (Figure 3b). However, Aln-induced death was enhanced by APC and this effect increased as the concentration of Aln increased (Figure 3c). This inhibitory effect of APC was apparent at $10 \mu \mathrm{g} \mathrm{ml}^{-1}$ but not at lower concentrations $(0.1$ or $1 \mu \mathrm{g} \mathrm{ml}^{-1}$; Figure $3 \mathrm{~d}$ ). These results were particularly robust and highlight an interesting phenomenon whereby APC reverses the cell-induced death induced by Zol or Pam, but enhances Aln-induced death. Apoptosis was measured using western blotting (Figure 4a) and immunofluorescence (Figure 4b) to detect active caspase-3. Both Aln and Zol induced active caspase-3, with Pam having no effect. The
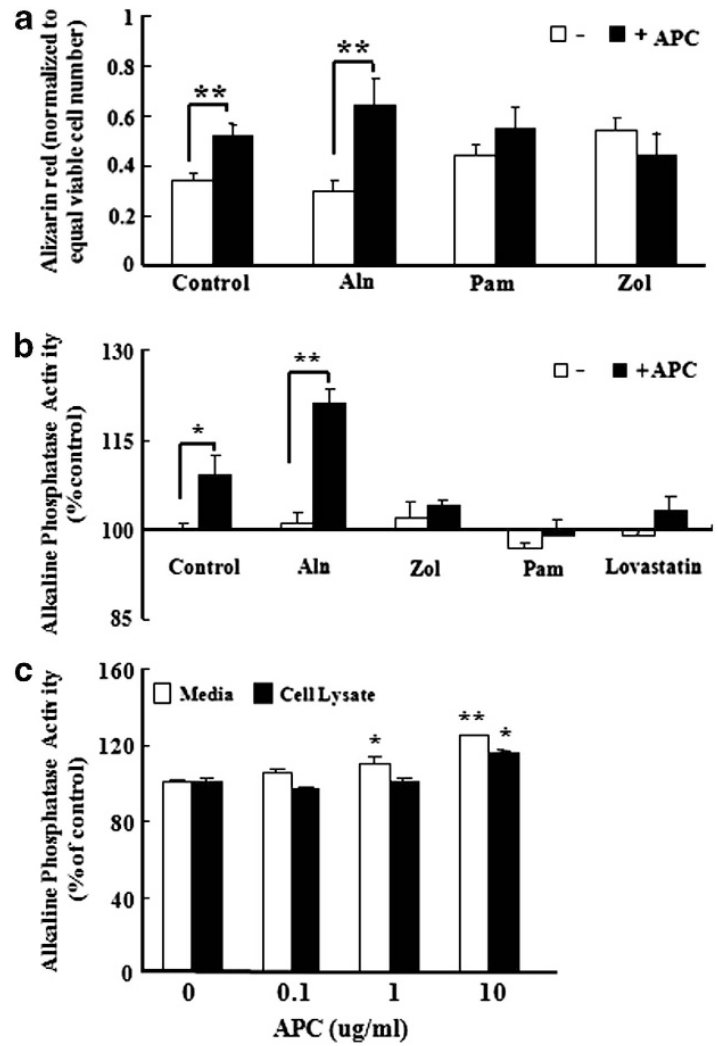

Figure 2 Activated protein C (APC) differentially affects MG63 differentiation depending on the presence of specific bisphosphonates. (a) Alizarin red staining performed in MG63 cells pretreated with APC $\left(10 \mu \mathrm{g} \mathrm{ml}^{-1}\right)$ for $1 \mathrm{~h}$ and/or cotreated with bisphosphonates (alendronate (Aln) $50 \mu \mathrm{m}$, pamidronate (Pam) $50 \mu \mathrm{m}$ and zoledronate (Zol) $50 \mu \mathrm{m}$ ) for $48 \mathrm{~h}$. The values were normalized to equal viable cell number. (b) Alkaline phosphatase activity tested in media of MG63 cells pretreated with APC $\left(10 \mu \mathrm{g} \mathrm{ml}^{-1}\right)$ for $1 \mathrm{~h}$ and/or cotreated with bisphosphonates (alendronate $50 \mu \mathrm{m}$, pamidronate $50 \mu \mathrm{m}$, zoledronate $50 \mu \mathrm{m}$ and lovastatin $5 \mu \mathrm{m}$ ) for $48 \mathrm{~h}$. (c) Alkaline phosphatase activity tested in media and cell lysate of MG63 cells cultured with APC $(0.1,1$ and $10 \mu \mathrm{g} \mathrm{ml}^{-1}$ ) for $48 \mathrm{~h} .{ }^{*} P<0.05 ;{ }^{*} P<0.01$ versus control group.

addition of APC for $24 \mathrm{~h}$ enhanced active caspase and cell death in response to Aln but had minimal effect in response to Zol and Pam.

EPCR is expressed by MG63 cells and upregulated by APC We attempted to determine whether there exists a common pathway through which both Aln and APC may act. We examined three molecules involved in well-described effects of APC; MMP-2, nuclear factor (NF)-KB and ERK1/2. Total proMMP-2 and active-MMP-2, measured by zymography, was inhibited by Aln in a dose-responsive manner (Figure 5). The addition of APC restored the level of pro-MMP-2 and highly induced MMP-2 activation in the presence or absence of Aln (Figure 5). Active NF- $\mathrm{KB}$ was dose-dependently increased by Aln and inhibited by APC treatment (Figure 5). In contrast, phosphorylation of the mitogen-activated protein kinase, ERK1/2, was increased by both Aln and APC, with the APC causing a marked induction of p-ERK (Figure 5). 

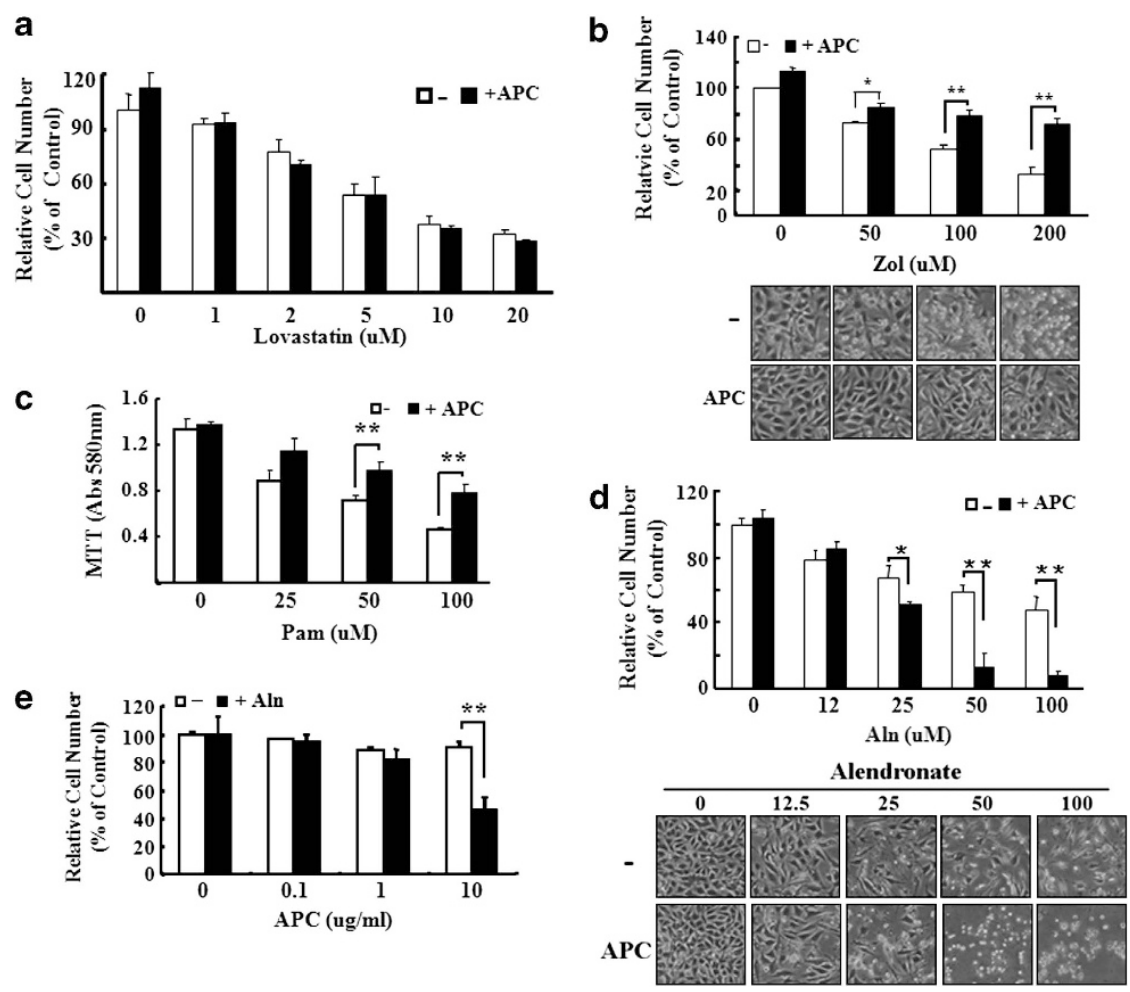

Figure 3 Activated protein C (APC) exerts opposing effects on MG63 viability depending on the presence of specific bisphosphonates. (a) MG63 cells were pretreated with or without $10 \mu \mathrm{g} \mathrm{ml}-1$ of APC for $1 \mathrm{~h}$ and then cotreated with lovastatin for $48 \mathrm{~h}$. Cell numbers were determined by crystal violet assay and expressed as the percentage of control cells. (b) MG63 cells were pretreated with or without $10 \mu \mathrm{g} \mathrm{ml}^{-1}$ of APC for $1 \mathrm{~h}$ and then cotreated with zoledronate (Zol; 50, 100 and $200 \mu \mathrm{m}$ ) for $48 \mathrm{~h}$. Cell numbers were determined by crystal violet assay and expressed as the percentage of control cells. Cell morphology under the conditions was photographed $(\times 200$ ). (c) MG63 cells plated in 96-well were pretreated to $10 \mu \mathrm{g} \mathrm{ml}^{-1}$ of APC for $1 \mathrm{~h}$ and then cotreated with pamidronate (Pam) for $48 \mathrm{~h}$. Cell viability was determined by MTT assay. Viability of control cells was set at $100 \%$, and viability relative to the control was presented. (d) MG63 cells were pretreated with or without $10 \mu \mathrm{g} \mathrm{ml} \mathrm{l}^{-1}$ of APC for $1 \mathrm{~h}$ and then cotreated with alendronate (Aln; $12,25,50$ and $100 \mu \mathrm{m})$ for $48 \mathrm{~h}$. Cell numbers were determined by crystal violet assay and expressed as the percentage of control cells. Cell morphology under the conditions was photographed $(\times 200)$. (e) MG63 cells were pretreated with APC $\left(0.1,1\right.$ and $\left.10 \mu g \mathrm{ml}^{-1}\right)$ for $1 \mathrm{~h}$ and then cotreated with $100 \mu \mathrm{m}$ of alendronate. ${ }^{*} P<0.05 ;{ }^{*} P<0.01$ versus control group.

MG63 preosteoblast osteosarcoma cells were maintained in serum-free medium for $24 \mathrm{~h}$ to remove any soluble EPCR, and then washed and assessed for EPCR expression using immunoblotting and immunohistochemistry. Cultured MG63 monolayers stained positive for EPCR using immunofluorescence under basal conditions. In response to APC, EPCR staining intensity was dose-dependently increased (Figure 6a). EPCR protein was also detected in the cell lysates of MG63 cells by immunoblotting (Figure 6b). Treatment of cells with Aln dose-dependently increased EPCR expression (Figure 6b). The addition of APC to Aln exerted no additional increase in EPCR. In contrast, Pam or Zol had no effect on EPCR expression (data not shown).

Many of the protective effects of APC are mediated through EPCR in endothelial cells and keratinocytes. We investigated whether the actions APC on cell viability in the presence of Zol or Aln require EPCR by using RCR252, an antibody that prevents APC from binding to its receptor. When RCR252 was added to cells treated with Zol plus APC, there was a significant reduction in cell viability (Figure 6c). However, when added to cells treated with Aln plus APC, there was no change in cell viability. This indicates that whereas the cytoprotective effect of APC in the presence of Zol is mediated through EPCR, its damaging effect in the presence of Aln is not mediated through this recepetor.

\section{DISCUSSION}

The therapeutic effect of BPs is thought to be derived from their ability to suppress osteoclast activity, through inhibition of prenylation. ${ }^{19,20}$ A number of reports have also shown that BPs stimulate proliferation and exert antiapoptotic affects on both osteoblasts and osteocytes. ${ }^{5,6,21-23}$ These effects appear to be mediated via a different pathway to the proapoptotic effect of BPss on osteoclasts, and involve connexin 43 (Plotkin et al. ${ }^{22}$ ) and ERK activation. ${ }^{24}$ In contrast, our study shows that BPs inhibit the survival of the osteoblast line, MG63, at least partly by increasing the activity of the proapoptotic enzyme, caspase-3. This paradox may be explained by differential dose-dependent responses of osteoblasts to $\mathrm{BPs}^{25}$ and heterogeneity in their effects. Studies that found that 


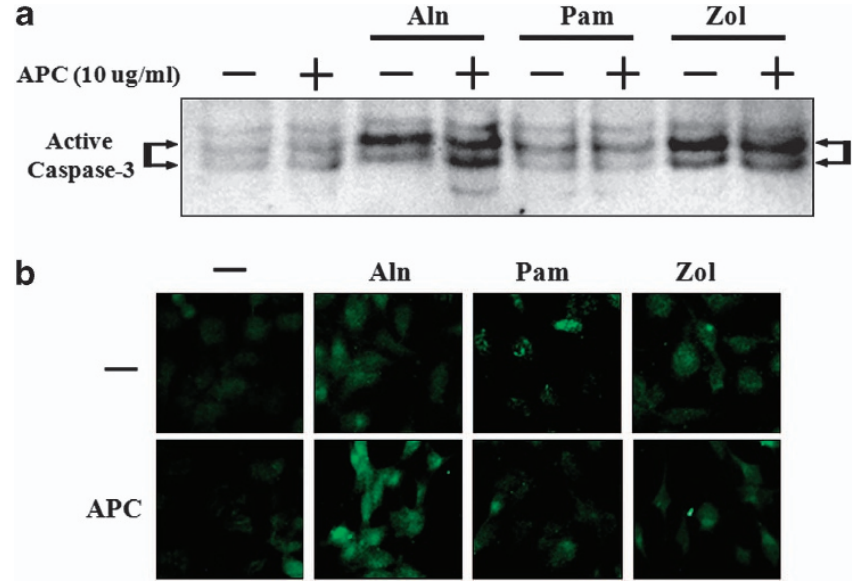

Figure 4 Activated protein C (APC) differentially affects the caspase activity on MG63 viability depending on the presence of specific bisphosphonates. MG63 cells were pretreated with APC $\left(10 \mu \mathrm{gl}^{-1}\right)$ for $1 \mathrm{~h}$ and/or cotreated with bisphosphonates (alendronate (Aln) $100 \mu \mathrm{m}$, pamidronate (Pam) $100 \mu \mathrm{m}$ and zoledronate (Zol) $100 \mu \mathrm{m}$ ) for $24 \mathrm{~h}$ and active caspase-3 detected using western blotting (a), detected by immunofluorescence staining (b).
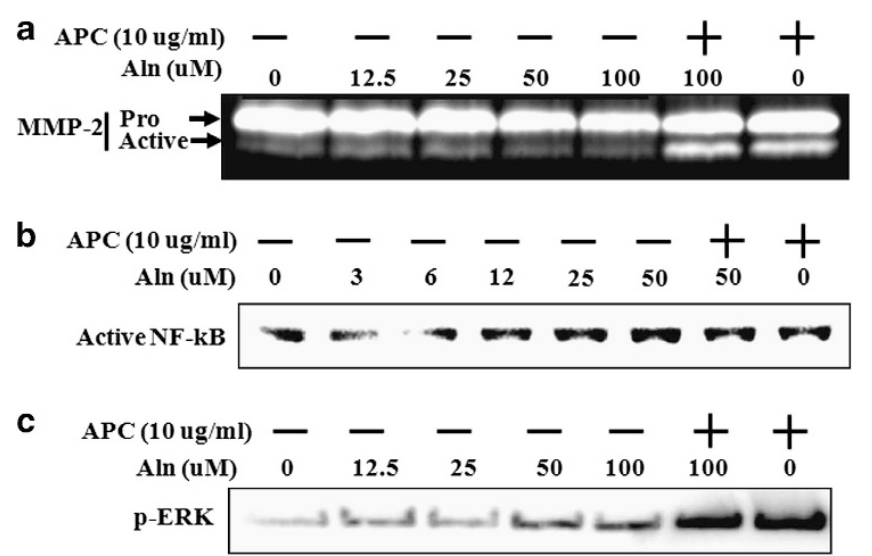

Figure 5 Activated protein $\mathrm{C}$ (APC) activated the matrix metalloproteinase-2 (MMP-2), nuclear factor (NF)- $\mathrm{KB}$ and extracellular signal-regulated kinase (ERK) protein in MG63 cells. (a) Pro-MMP-2 and active-MMP-2 were detected using gelatine zymography in MG63 cell lysates pretreated with APC $\left(10 \mu \mathrm{g} \mathrm{ml}^{-1}\right)$ for $1 \mathrm{~h}$ and/or cotreated with alendronate (Aln; 12.5, 25, 50 and $100 \mu \mathrm{m})$ for $24 \mathrm{~h}$. (b) MG63 cells were pretreated with APC $\left(10 \mu \mathrm{gl}^{-1}\right)$ for $1 \mathrm{~h}$ and/or cotreated with $\operatorname{Aln}(3,6,12,25,50$ or $100 \mu \mathrm{m})$ for $24 \mathrm{~h}$, and cell lysates were analyzed by western blotting using antibodies for (b) active NF-KB and (c) phospho-ERK.

BPs stimulate osteoblast survival used nM concentrations, whereas our study used BPs in the $\mu \mathrm{m}$ range, which approximates the concentration at which they inhibit osteoclast proliferation. Our findings are in agreement with other reports that use similar concentrations of BPs. Reinholz et al. ${ }^{26}$ found that Pam and Aln dose-dependently inhibit proliferation of immortalized normal human osteoblasts. Idris et al. ${ }^{27}$ have recently reported that BPs exert strong inhibitory effects on cells of the osteoblast lineage at similar concentrations to those

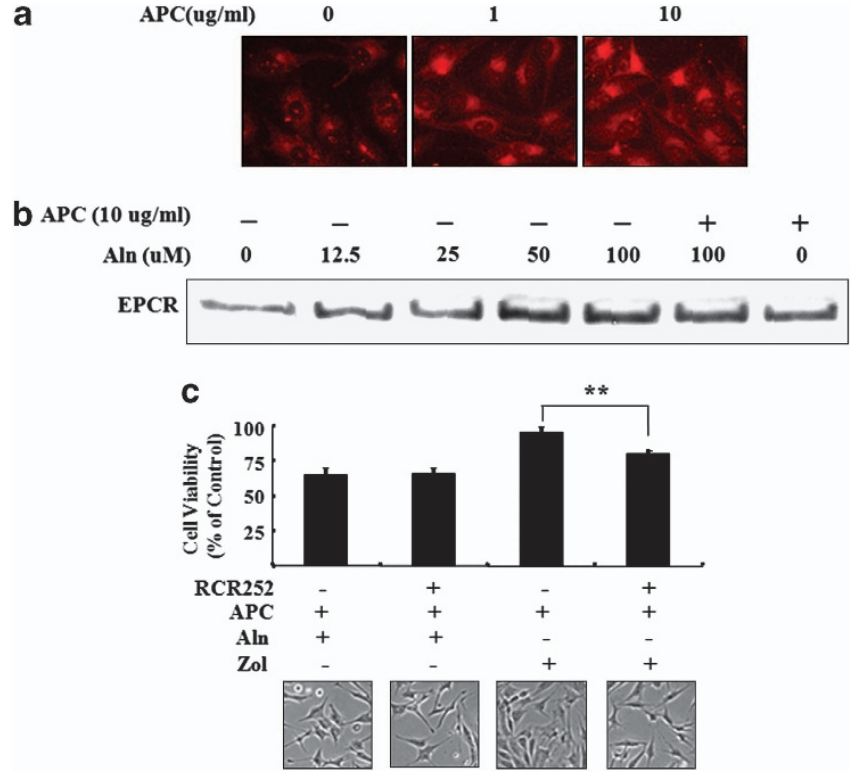

Figure 6 Endothelial protein $C$ receptor (EPCR) is expressed by MG63 cells and upregulated by activated protein C (APC). (a) MG63 cells were treated with APC ( 1 and $\left.10 \mu \mathrm{g} \mathrm{ml}^{-1}\right)$ for $25 \mathrm{~h}$, and cells were immunostained with EPCR antibody, and photographed in fluorescence microscopy analysis. (b) MG63 cells were pretreated with APC $\left(10 \mu \mathrm{gml}^{-1}\right)$ for $1 \mathrm{~h}$ and/or cotreated with alendronate (Aln; 12.5, 25, 50 and $100 \mu \mathrm{m}$ for $24 \mathrm{~h}$, and cell lysates were analyzed by western blotting using antibodies for EPCR. (c) MG63 cells were pretreated with $10 \mu \mathrm{g} \mathrm{ml} \mathrm{m}^{-1}$ of EPCR blocking antibodies (RCR-252) and $10 \mu \mathrm{g} \mathrm{ml}^{-1}$ of APC for $1 \mathrm{~h}$, and cotreated with Aln (100 $\mu \mathrm{m})$ and zoledronate (Zol; $100 \mu \mathrm{m})$ for $48 \mathrm{~h}$. ${ }^{* *} P<0.01$ versus control group.

that cause osteoclast inhibition, and suggested that BPs may act beneficially in this way to inhibit bone nodule formation. In vivo, BPs suppress periosteal osteoblast activity and bone formation at clinical dose levels, independently of resorption in rat femus and tibia, ${ }^{28}$ which may explain the reduced therapeutic effects of teriparatide, a recombinant form of parathyroid hormone, when administered concurrently with BPs. ${ }^{28}$

A single recent pubication shows that APC can stimulate osteoblast proliferation via EPCR. ${ }^{29}$ The effects of APC on osteoblast differentiation or in the presence of BPs have not previously been published. Our results show that under basal conditions APC promotes MG63 differentiation as assessed by increased type 1 collagen production, Alizarin red staining and ALP activity. APC also enhanced type 1 collagen production in MG63 cells in the presence of all three BPs. However, APC exerted different effects on MG63 Alizarin red staining and ALP activity, depending on the presence of specific BPs. These two markers of MG63 differentiation were maintained at high levels in the presence of Aln, but not Pam or Zol. In a similar manner, APC exerted different effects on MG63 viability in the presence of different BPs. When used alone, APC did not affect viability of confluent cells; however, in the presence of Aln it substantially reduced and in the presence of Pam or Zol it enhanced viability. These disparate effects of APC were 
consistent over multiple experiments. The exact mechanisms to explain these actions of APC need further investigation.

Here we show that an osteoblast lineage strongly expresses the receptor for APC, EPCR. This receptor was first identified on endothelial cells, mainly on larger blood vessels ${ }^{30}$ and recently has been found on leukocytes, smooth muscle cells and keratinocytes. ${ }^{3,31-34}$ In addition to being involved in the activation of PC, EPCR has significant anti-inflammatory properties. ${ }^{35,36}$ For example, severe EPCR deficiency adversely affects survival and cardiac function of mice subjected to challenge by endotoxin infusion. ${ }^{37}$ Baboons treated with an antibody to block PC binding to EPCR respond lethally to normally sublethal concentrations of Escherichia coli and exhibit disseminated intravascular coagulation, intense neutrophil influx into the tissues and elevation of inflammatory cytokines, indicating that EPCR provides a critical step in the host defense against $E$ coli. ${ }^{36}$ The current study provides new data that corroborate on these findings to show that whereas inhibition of survival of APC in the presence of Aln is independent of EPCR, the favorable actions of APC on MG63 survival in response to Zol are mediated through EPCR (Figure 5c). Although EPCR mediates this protective effect of APC, there is no evidence that it is a signaling molecule. Instead, by binding to EPCR, APC may cleave protease activated receptor- 1 that couples to G-proteins and signals through mitogen-activated protein kinases. Although it is unknown whether APC acts through this pathway in osteoblasts, we provide evidence that APC strongly activates the mitogen-activated protein kinase, ERK1/2. These results are in accord with recent studies using endothelial cells and keratinocytes that found that APC induces cell proliferation via activation of the ERK1/2 pathway. $3,31-34,38,39$

Strong evidence is now emerging that the PC pathway contributes to wound repair. APC stimulates proliferation, migration, MMP-2 production and prevents apoptosis in human skin keratinocytes. ${ }^{40}$ Uchiba et al. ${ }^{38}$ have shown that APC acts through EPCR to stimulate proliferation and tube formation of cultured endothelial cells and promote angiogenesis in the rabbit corneal assay. In a rat healing model, APC induces angiogenesis and re-epithelialization while inhibiting inflammation to promote cutaneous wound healing. ${ }^{39}$ In a recent pilot human trial, APC stimulated wound healing in patients with skin ulcers refractory to conventional wound healing therapies. ${ }^{17}$ APC also promotes the growth, MMP-2 activity, type I collagen deposition and migration of tenocytes, implicating it as a potential healing agent for injured tendons. ${ }^{16}$ The current study shows that two vital processes of bone remodeling, osteoblast survival and differentiation, are enhanced by APC. These data provide the first evidence that, in addition to skin and tendon healing, APC may promote healing of bone and be of therapeutic value in certain bone disorders, such as ONJ, where it may contribute to both hard and soft tissue healing. ${ }^{41}$ However, there appears to be an important caveat with the use of APC to treat patients on BPs. Our results clearly indicate that APC reverses the damaging effects of survival by Pam and Zol, but enhances osteoblast death induced by Aln. Furthermore, the opposite effect is seen on cell differentiation, where APC enhances the beneficial effect of Aln, but Pam and Zol inhibit the effect of APC. Extrapolation of these results to the clinic would indicate that the use of APC in patients on BPs should be considered and monitored carefully.

In summary, we have demonstrated for the first time that (1) APC favorably regulates MG63 viability and differentiation toward bone growth, (2) APC differnetially regulates the effects of specific BPs on viability and differentiation and (3) at least part of the effects of APC is mediated through EPCR. These findings highlight the potential importance of the $\mathrm{PC}$ pathway in bone physiology and provides the first evidence that APC may reverse bone damage and has potential to be a therapeutic drug for bone regeneration.

\section{CONFLICT OF INTEREST}

The authors declare no conflict of interest.

\section{ACKNOWLEDGEMENTS}

This study was supported by a grant from the National Research Foundation of Korea funded by the Korean Government (2010-E00019).

1 Assael LA. Oral bisphosphonates as a cause of bisphosphonate-related osteonecrosis of the jaws: clinical findings, assessment of risks, and preventive strategies. J Oral Maxillofac Surg 2009; 67: 35-43.

2 Khosla S, Burr D, Cauley J, Dempster DW, Ebeling PR, Felsenberg D et al. Bisphosphonate-associated osteonecrosis of the jaw: report of a task force of the American Society for Bone and Mineral Research. J Bone Miner Res 2007; 22: 1479-1491.

3 Xue M, Campbell D, Sambrook PN, Fukudome K, Jackson CJ. Endothelial protein $\mathrm{C}$ receptor and protease-activated receptor- 1 mediate induction of a wound-healing phenotype in human keratinocytes by activated protein $\mathrm{C}$. J Invest Dermatol 2005; 125: 1279-1285.

4 Reid IR, Bolland MJ, Grey AB. Is bisphosphonate-associated osteonecrosis of the jaw caused by soft tissue toxicity? Bone 2007; 41: 318-320.

5 Plotkin LI, Manolagas SC, Bellido T. Dissociation of the pro-apoptotic effects of bisphosphonates on osteoclasts from their anti-apoptotic effects on osteoblasts/osteocytes with novel analogs. Bone 2006; 39: 443-452.

6 Plotkin LI, Weinstein RS, Parfitt AM, Roberson PK, Manolagas SC, Bellido T. Prevention of osteocyte and osteoblast apoptosis by bisphosphonates and calcitonin. J Clin Invest 1999; 104: 1363-1374.

7 Giuliani N, Pedrazzoni M, Negri G, Passeri G, Impicciatore M, Girasole G. Bisphosphonates stimulate formation of osteoblast precursors and mineralized nodules in murine and human bone marrow cultures in vitro and promote early osteoblastogenesis in young and aged mice in vivo. Bone 1998; 22: 455-461.

8 Duque G, Rivas D. Alendronate has an anabolic effect on bone through the differentiation of mesenchymal stem cells. J Bone Miner Res 2007; 22: 1603-1611.

9 Tobias JH, Chow JW, Chambers TJ. 3-Amino-1-hydroxypropylidine-1bisphosphonate (AHPrBP) suppresses not only the induction of new, but also the persistence of existing bone-forming surfaces in rat cancellous bone. Bone 1993; 14: 619-623.

10 Black DM, Bilezikian JP, Ensrud KE, Greenspan SL, Palermo L, Hue T et al. One year of alendronate after one year of parathyroid hormone (1-84) for osteoporosis. N Engl J Med 2005; 353: 555-565.

11 Delmas PD, Vergnaud P, Arlot ME, Pastoureau P, Meunier PJ, Nilssen MH The anabolic effect of human PTH (1-34) on bone formation is blunted when bone resorption is inhibited by the bisphosphonate tiludronate-is activated resorption a prerequisite for the in vivo effect of PTH on formation in a remodeling system? Bone 1995; 16: 603-610. 
12 Ettinger B, San Martin J, Crans G, Pavo I. Differential effects of teriparatide on $\mathrm{BMD}$ after treatment with raloxifene or alendronate. J Bone Miner Res 2004; 19: 745-751.

13 Finkelstein JS, Hayes A, Hunzelman JL, Wyland JJ, Lee H, Neer RM. The effects of parathyroid hormone, alendronate, or both in men with osteoporosis. N Engl J Med 2003; 349: 1216-1226.

14 Gasser JA, Kneissel M, Thomsen JS, Mosekilde L. PTH and interactions with bisphosphonates. J Musculoskelet Neuronal Interact 2000; 1: 53-56.

15 Samadfam R, Xia Q, Goltzman D. Pretreatment with anticatabolic agents blunts but does not eliminate the skeletal anabolic response to parathyroid hormone in oophorectomized mice. Endocrinology 2007; 148: $2778-2787$

16 Xue M, Jackson CJ. Autocrine actions of matrix metalloproteinase (MMP)-2 counter the effects of MMP-9 to promote survival and prevent terminal differentiation of cultured human keratinocytes. J Invest Dermatol 2008; 128: 2676-2685.

17 Whitmont K, Reid I, Tritton S, March L, Xue M, Lee M et al. Treatment of chronic leg ulcers with topical activated protein C. Arch Dermatol 2008; 144: 1479-1483.

18 Herron GS, Banda MJ, Clark EJ, Gavrilovic J, Werb Z. Secretion of metalloproteinases by stimulated capillary endothelial cells. II. Expression of collagenase and stromelysin activities is regulated by endogenous inhibitors. J Biol Chem 1986; 261: 2814-2818.

19 Green JR. Chemical and biological prerequisites for novel bisphosphonate molecules: results of comparative preclinical studies. Semin Oncol 2001; 28: 4-10.

20 Rogers MJ, Gordon S, Benford HL, Coxon FP, Luckman SP, Monkkonen J et al. Cellular and molecular mechanisms of action of bisphosphonates. Cancer 2000; 88: 2961-2978.

21 Follet H, Li J, Phipps RJ, Hui S, Condon K, Burr DB. Risedronate and alendronate suppress osteocyte apoptosis following cyclic fatigue loading. Bone 2007; 40: 1172-1177.

22 Plotkin LI, Lezcano V, Thostenson J, Weinstein RS, Manolagas SC, Bellido T. Connexin 43 is required for the anti-apoptotic effect of bisphosphonates on osteocytes and osteoblasts in vivo. J Bone Miner Res 2008; 23: 1712-1721.

23 von Knoch F, Jaquiery C, Kowalsky M, Schaeren S, Alabre C, Martin I et al. Effects of bisphosphonates on proliferation and osteoblast differentiation of human bone marrow stromal cells. Biomaterials 2005; 26: 6941-6949.

24 Plotkin LI, Aguirre JI, Kousteni S, Manolagas SC, Bellido T. Bisphosphonates and estrogens inhibit osteocyte apoptosis via distinct molecular mechanisms downstream of extracellular signal-regulated kinase activation. J Biol Chem 2005; 280: 7317-7325.

25 Russell RG. Bisphosphonates: from bench to bedside. Ann N Y Acad Sci 2006; 1068: 367-401.

26 Reinholz GG, Getz B, Pederson L, Sanders ES, Subramaniam M, Ingle JN et al. Bisphosphonates directly regulate cell proliferation, differentiation, and gene expression in human osteoblasts. Cancer Res 2000; 60: 6001-6007.

27 Idris Al, Rojas J, Greig IR, Van't Hof RJ, Ralston SH. Aminobisphosphonates cause osteoblast apoptosis and inhibit bone nodule formation in vitro. Calcif Tissue Int 2008; 82: 191-201.
28 Iwata K, Li J, Follet H, Phipps RJ, Burr DB. Bisphosphonates suppress periosteal osteoblast activity independently of resorption in rat femur and tibia. Bone 2006; 39: 1053-1058.

29 Kurata T, Hayashi T, Yoshikawa T, Okamoto T, Yoshida K, lino T et al. Activated protein $\mathrm{C}$ stimulates osteoblast proliferation via endothelial protein C receptor. Thromb Res 2010; 125: 184-191.

30 Laszik Z, Mitro A, Taylor FB Jr, Ferrell G, Esmon CT. Human protein C receptor is present primarily on endothelium of large blood vessels: implications for the control of the protein C pathway. Circulation 1997; 96: 3633-3640.

31 Feistritzer C, Sturn DH, Kaneider NC, Djanani A, Wiedermann CJ. Endothelial protein $C$ receptor-dependent inhibition of human eosinophil chemotaxis by protein C. J Allergy Clin Immunol 2003; 112: 375-381.

32 Galligan L, Livingstone W, Volkov Y, Hokamp K, Murphy C, Lawler M et al. Characterization of protein $\mathrm{C}$ receptor expression in monocytes. $\mathrm{Br} \mathrm{J}$ Haematol 2001; 115: 408-414.

33 Joyce DE, Nelson DR, Grinnell BW. Leukocyte and endothelial cell interactions in sepsis: relevance of the protein $\mathrm{C}$ pathway. Crit Care Med 2004; 32: S280-S286.

34 Sturn DH, Kaneider NC, Feistritzer C, Djanani A, Fukudome K, Wiedermann CJ. Expression and function of the endothelial protein $\mathrm{C}$ receptor in human neutrophils. Blood 2003; 102: 1499-1505.

35 Esmon CT. Crosstalk between inflammation and thrombosis. Maturitas 2008; 61: 122-131.

36 Taylor FB Jr, Stearns-Kurosawa DJ, Kurosawa S, Ferrell G, Chang AC, Laszik $Z$ et al. The endothelial cell protein $C$ receptor aids in host defense against Escherichia coli sepsis. Blood 2000; 95: 1680-1686.

37 Iwaki T, Cruz DT, Martin JA, Castellino FJ. A cardioprotective role for the endothelial protein $C$ receptor in lipopolysaccharide-induced endotoxemia in the mouse. Blood 2005; 105: 2364-2371.

38 Uchiba M, Okajima K, Oike Y, Ito Y, Fukudome K, Isobe H et al. Activated protein $\mathrm{C}$ induces endothelial cell proliferation by mitogen-activated protein kinase activation in vitro and angiogenesis in vivo. Circ Res 2004; 95: 34-41.

39 Jackson CJ, Xue M, Thompson P, Davey RA, Whitmont K, Smith S et al. Activated protein $C$ prevents inflammation yet stimulates angiogenesis to promote cutaneous wound healing. Wound Repair Regen 2005; 13: 284-294.

40 Xue M, Thompson P, Kelso I, Jackson C. Activated protein C stimulates proliferation, migration and wound closure, inhibits apoptosis and upregulates MMP-2 activity in cultured human keratinocytes. Exp Cell Res 2004; 299: 119-127.

41 Jackson CJ, Xue M. Activated protein C-an anticoagulant that does more than stop clots. Int J Biochem Cell Biol 2008; 40: 2692-2697.

(c) $(1) \Theta \Theta$ This work is licensed under a Creative Commons
Attribution-NonCommercial-NoDerivs 3.0 Un-
ported License. To view a copy of this license, visit http://
creativecommons.org/licenses/by-nc-nd/3.0/

